\title{
Appendix
}

\section{The Bologna Declaration of 19 June 1999}

\section{Joint Declaration of the European Ministers of Education}

The European process, thanks to the extraordinary achievements of the last few years, has become an increasingly concrete and relevant reality for the Union and its citizens. Enlargement prospects together with deepening relations with other European countries provide even wider dimensions to that reality. Meanwhile, we are witnessing a growing awareness in large parts of the political and academic world and in public opinion of the need to establish a more complete and far-reaching Europe, in particular building upon and strengthening its intellectual, cultural, social and scientific and technological dimensions.

A Europe of Knowledge is now widely recognised as an irreplaceable factor for social and human growth and as an indispensable component to consolidate and enrich the European citizenship, capable of giving its citizens the necessary competences to face the challenges of the new millennium, together with an awareness of shared values and belonging to a common social and cultural space.

The importance of education and educational co-operation in the development and strengthening of stable, peaceful and democratic societies is universally acknowledged as paramount, the more so in view of the situation in South East Europe.

The Sorbonne declaration of 25th of May 1998, which was underpinned by these considerations, stressed the Universities' central role in developing European cultural dimensions. It emphasised the creation of the European area of higher education as a key way to promote citizens' mobility and employability and the Continent's overall development.

Several European countries have accepted the invitation to commit themselves to achieving the objectives set out in the declaration, by signing it or expressing their agreement in principle. The direction taken by several higher education reforms launched in the meantime in Europe has proved many Governments' determination to act.

European higher education institutions, for their part, have accepted the challenge and taken up a main role in constructing the European 
area of higher education, also in the wake of the fundamental principles laid down in the Bologna Magna Charta Universitatum of 1988. This is of the highest importance, given that universities' independence and autonomy ensure that higher education and research systems continuously adapt to changing needs, society's demands and advances in scientific knowledge.

The course has been set in the right direction and with meaningful purpose. The achievement of greater compatibility of the systems of higher education nevertheless requires continual momentum in order to be fully accomplished. We need to support it through promoting concrete measures to achieve tangible forward steps; the 18th June meeting saw participation by authoritative experts and scholars from all our countries and provides us with very useful suggestions on the initiatives to be taken.

We must, in particular, look at the objective of increasing the international competitiveness of the European system of higher education. The vitality and efficiency of any civilisation can be measured by the appeal that its culture has for other countries. We need to ensure that the European higher education system acquires a world-wide degree of attraction equal to our extraordinary cultural and scientific traditions.

While affirming our support to the general principles laid down in the Sorbonne declaration, we engage in co-ordinating our policies to reach in the short term, and in any case within the first decade of the third millennium, the following objectives, which we consider to be of primary relevance in order to establish the European area of higher education and to promote the European system of higher education world-wide:

Adoption of a system of easily readable and comparable degrees, also through the implementation of the Diploma Supplement, in order to promote European citizen's employability and the international competitiveness of the European higher education system.

Adoption of a system essentially based on two main cycles, undergraduate and graduate. Access to the second cycle shall require successful completion of first cycle studies, lasting a minimum of three years. The degree awarded after the first cycle shall also be relevant to the European labour market as an appropriate level of qualification; the second cycle should lead to the master and/or doctorate degree as in many European countries. 
Establishment of a system of credits - such as in the ECTS system - as a proper means of promoting the most widespread student mobility. Credits could also be acquired in non-higher education contexts, including lifelong learning, provided they are recognised by receiving universities concerned.

Promotion of mobility by overcoming obstacles to the effective exercise of free movement with particular attention to:

- for students, access to study and training opportunities and to related services;

- for teachers, researchers and administrative staff, recognition and valorisation of periods spent in a European context researching, teaching and training, without prejudicing their statutory rights.

Promotion of European co-operation in quality assurance with a view to developing comparable criteria and methodologies.

Promotion of the necessary European dimensions in higher education, particularly with regards to curricular development, inter-institutional co-operation, mobility schemes and integrated programmes of study, training and research.

We hereby undertake to attain these objectives - within the framework of our institutional competences and taking full respect of the diversity of cultures, languages, national education systems and of university autonomy - to consolidate the European area of higher education. To that end, we will pursue the ways of intergovernmental co-operation, together with those of non-governmental European organisations with competence on higher education. We expect universities again to respond promptly and positively and to contribute actively to the success of our endeavour.

Convinced that the establishment of the European area of higher education requires constant support, supervision and adaptation to the continuously evolving needs, we decide to meet again within two years in order to assess the progress achieved and the new steps to be taken.

\section{Signatories}

Ministers of Education or their representatives from:

Austria, Belgium (Flemish Community), Belgium (French Community), Bulgaria, Czech Republic, Denmark, Estonia, Finland, France, Germany 
186 Appendix

(Federal Ministry), Germany (Representative of the Länder), Greece, Hungary, Iceland, Ireland, Italy, Latvia, Lithuania, Luxembourg. Malta, the Netherlands, Norway, Poland, Portugal, Romania, Slovakia, Slovenia, Spain, Sweden, Switzerland, United Kingdom.

Transcribed from: www.ehea.info/Uploads/about/BOLOGNA-DECL ARATION1.pdf 